\title{
Fat absorption in congenital obstructive liver disease
}

\author{
J. F. T. GLASGOW, J. R. HAMILTON, and A. SASS-KORTSAK \\ From the Department of Paediatrics, University of Toronto, and The Research Institute of the Hospital for Sick Children, \\ Toronto, Ontario, Canada
}

\begin{abstract}
Glasgow, J. F. T., Hamilton, J. R., and Sass-Kortsak, A. (1973). Archives of Disease in Childhood, 48, 601. Fat absorption in congenital obstructive liver disease. Fat absorption was impaired in 11 of 15 children with congenital obstructive liver disease. Lecithin administered by mouth to 7 patients failed to improve fat absorption. Proximal intestinal contents sampled during digestion of a standard fat-containing meal showed impaired solubilization of lipid in the aqueous phase, which reflected the severity of the steatorrhoea. There was a close positive correlation between the degree of fat solubilization and the luminal concentration of bile salts. A proportion of dietary fat was solubilized and absorbed even in the absence of detectable bile salts. This study underlines the importance both of bile salts in normal assimilation of fat and of alternative absorptive pathways in biliary obstruction.
\end{abstract}

We studied 15 infants with congenital obstructive liver disease to determine the nature and degree of the defect in fat absorption associated with decreased concentrations of bile salts in duodenal contents. The occurrence of steatorrhoea in chronic liver disease is well known both in adults (Sun, Albacete, and Chen, 1967; Badley et al., 1970) and children (Burke and Danks, 1966), and Losowsky and Walker (1969) have reviewed likely pathogenetic mechanisms.

In normal adults the polar lipid products of the pancreatic lipolysis enter into a water-soluble, micellar complex with conjugated bile salts (Hofmann and Borgstrom, 1964). Recent studies in adult patients with nonalcoholic cirrhosis (Badley et al., 1970) and during the obstructive phase of infectious hepatitis (Modai and Theodor, 1970) have related the presence of steatorrhoea to the concentration of conjugated bile salts within the intestinal lumen during fat digestion. A better understanding of defects in the absorption of lipids should lead to improved management of their nutrition (Silverberg and Davidson, 1970; Weber and Roy, 1972).

\section{Material and methods}

We studied 15 children aged 2 to 93 months (Table I). All patients had been thoroughly investigated and all known causes of neonatal jaundice excluded. 8 had extrahepatic biliary atresia (EHBA) diagnosed on the

Received 27 December 1972. basis of faecal excretion of ${ }^{131}$ I labelled Rose-Bengal of less than $10 \%$ over 3 days (Ghadimi and Sass-Kortsak, 1961), visualization of the biliary remnants at laparotomy, operative cholangiography, and a clinical course compatible with this diagnosis. Of 7 children with chronic obstructive liver disease but patent bile ducts, 1 had $a_{1}$-antitrypsin deficiency, another had benign recurrent cholestasis (BRC), and the diagnosis of the remainder was called idiopathic obstructive jaundice (IOJ) because diagnostic studies failed to reveal a specific aetiology of the jaundice. 2 children with normal liver function and steatorrhoea due to a specific mucosal defect were used as controls for the intubation studies.

Studies were carried out in the Clinical Investigation Unit of the Hospital for Sick Children. We assessed liver function biochemically; serum concentrations of bilirubin, SGOT, and cholesterol and bromsulphalein (BSP) retention were determined by techniques described in a previous report from this hospital (Sass-Kortsak, Bowden, and Brown, 1956). Standard techniques were used to measure serum proteins by cellulose acetate electrophoresis, alkaline phosphatase (King and Wootton, 1956), inorganic phosphate (Gomori, 1942), calcium (MacIntyre, 1961), prothrombin time (PT), and partial thromboplastin time (PTT) (Hardisty and Ingram, 1965).

Faecal fat was measured (Van de Kamer, ten Bokkel Huinink, and Weyers, 1949) on pooled 5-day collections during which the recorded dietary fat intake exceeded $30 \mathrm{~g} /$ day. Cholestyramine and medium chain triglyceride dietary supplements were not administered during or within 4 days of the stool collection. In 9 patients with proven steatorrhoea ( 7 with extrahepatic biliary atresia, 2 with idiopathic obstructive jaundice) a second balance study was done during which the same 01 
Clinical and biochemizal

\begin{tabular}{|c|c|c|c|c|c|c|c|c|c|c|c|c|}
\hline Case no. & Diagnosis* & $\begin{array}{c}\text { Age } \\
\text { (mth) }\end{array}$ & Sex & $\begin{array}{l}\text { Height } \\
(\%)\end{array}$ & $\begin{array}{c}\text { Weight } \\
(\%)\end{array}$ & Diarrhoea & Haemorrhage & Pruritus & Xanthomata & $\begin{array}{c}\text { Portal } \\
\text { hyper- } \\
\text { tension }\end{array}$ & Ascites & 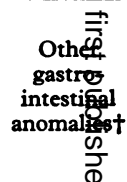 \\
\hline $\begin{array}{r}1 \\
2 \\
3 \\
4 \\
5 \\
6 \\
7 \\
8 \\
9 \\
10 \\
11 \\
12 \\
13 \\
14 \\
15\end{array}$ & $\begin{array}{l}\text { EHBA } \\
\text { EHBA } \\
\text { EHBA } \\
\text { EHBA } \\
\text { EHBA } \\
\text { EHBA } \\
\text { EHBA } \\
\text { EHBA } \\
\text { IOJ } \\
\text { IOJ } \\
\text { IOJ } \\
\text { BRC } \\
\text { IOJ } \\
\text { IOJ } \\
\alpha_{1} \text { AT } \\
\text { defic }\end{array}$ & $\begin{array}{r}12 \\
5 \\
18 \\
3 \\
4 \\
2 \\
3 \\
3 \\
71 \\
49 \\
2 \\
48 \\
36 \\
30 \\
\\
\\
93\end{array}$ & $\begin{array}{l}F \\
F \\
F \\
F \\
F \\
F \\
F \\
M \\
M \\
F \\
F \\
F \\
F \\
M \\
M\end{array}$ & $\begin{array}{r}<3 \\
3 \\
<3 \\
10 \\
50 \\
<3 \\
25 \\
50 \\
<3 \\
10 \\
10 \\
3 \\
75 \\
\\
50\end{array}$ & $\begin{array}{r}<3 \\
3 \\
<3 \\
<3 \\
10 \\
3 \\
<3 \\
10 \\
<3 \\
10 \\
10 \\
3 \\
50 \\
50 \\
\\
50\end{array}$ & $\begin{array}{l}- \\
- \\
= \\
z \\
= \\
\overline{-} \\
+ \\
= \\
= \\
- \\
- \\
-\end{array}$ & $\begin{array}{l}- \\
- \\
- \\
\overline{+} \\
- \\
- \\
- \\
\pm \\
- \\
- \\
- \\
- \\
+\end{array}$ & $\begin{array}{l}- \\
\overline{-} \\
- \\
- \\
- \\
\overline{-} \\
+ \\
\pm \\
+ \\
\pm \\
- \\
-\end{array}$ & $\begin{array}{l}- \\
\overline{-} \\
\overline{-} \\
- \\
\overline{-} \\
\overline{-} \\
+ \\
- \\
- \\
- \\
- \\
-\end{array}$ & $\begin{array}{l}+ \\
+ \\
+ \\
+ \\
- \\
- \\
- \\
+ \\
- \\
- \\
+ \\
- \\
+\end{array}$ & $\begin{array}{l}+ \\
\pm \\
+ \\
- \\
- \\
+ \\
- \\
- \\
- \\
- \\
- \\
- \\
- \\
-\end{array}$ & 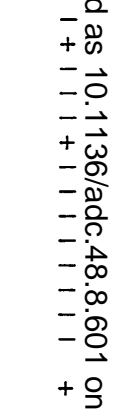 \\
\hline
\end{tabular}

^EHBA, extrahepatic biliary atresia; IOJ, idiopathic obstructive jaundice; BRC, benign recurrent cholestasis; $\alpha_{1}$ AT defic, alpha 1 -antitryp tCases 2 and 6: partial malrotation of small bowel corrected at laparotomy.

fat intake was supplemented with egg lecithin, $\star 1 \mathrm{~g}$ lecithin to $5 \mathrm{~g}$ dietary fat. We assessed the intestinal absorption of vitamin A indirectly by measuring serum levels of the vitamin before and 3,5 , and 7 hours after the oral administration of $12,000 \mathrm{IU} / \mathrm{kg}$ bodyweight. All

^B.D.H. Chemicals Ltd., Poole, Dorset. patients had received vitamin A supplements until the time of the test.

Intestinal intubation studies were carried out after an overnight fast with the patient lightly sedated. We sampled intestinal contents with a radio-opaque polyvinyl tube positioned with its tip 2 to $5 \mathrm{~cm}$ beyond the ligament of Treitz. A freshly emulsified test meal $(7.5 \mathrm{~g}$ corn

TABDE

Lipid absorption

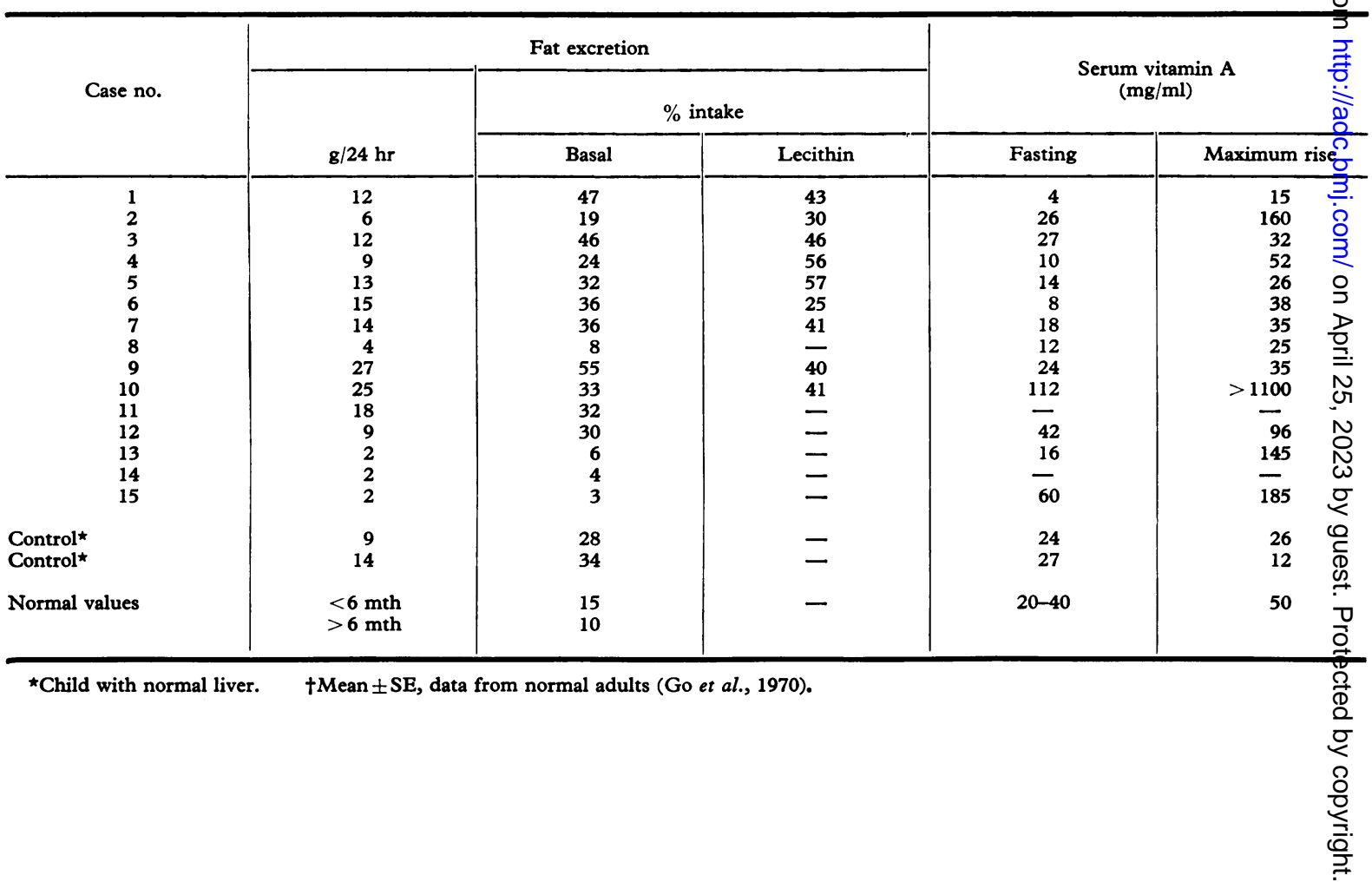


data in 15 cases

\begin{tabular}{|c|c|c|c|c|c|c|c|c|c|}
\hline \multicolumn{10}{|c|}{ Blood tests } \\
\hline \multicolumn{2}{|c|}{$\underset{(\mathrm{mg} / 100 \mathrm{ml})}{\text { Bilirubin }}$} & \multirow{2}{*}{$\begin{array}{l}\text { Albumin } \\
(\mathrm{g} / 100 \mathrm{ml})\end{array}$} & \multirow{2}{*}{$\begin{array}{c}\text { Prothrombin } \\
\text { times } \\
(\mathrm{sec})\end{array}$} & \multirow{2}{*}{$\begin{array}{c}\text { Partial } \\
\text { thromboplastin } \\
\text { times } \\
(\mathrm{sec})\end{array}$} & \multirow{2}{*}{$\underset{\text { (units/ml) }}{\text { SGOT }}$} & \multirow{2}{*}{$\begin{array}{c}\text { Alkaline } \\
\text { phosphatase } \\
\text { (KA units/ml) }\end{array}$} & \multirow{2}{*}{$\begin{array}{l}\text { Cholesterol } \\
(\mathrm{mg} / 100 \mathrm{ml})\end{array}$} & \multirow{2}{*}{$\begin{array}{c}\text { Calcium } \\
(\mathrm{mg} / 100 \mathrm{ml})\end{array}$} & \multirow{2}{*}{$\begin{array}{l}\text { Phosphorus } \\
(\mathrm{mg} / 100 \mathrm{ml})\end{array}$} \\
\hline Total & Direct & & & & & & & & \\
\hline $\begin{array}{r}11 \cdot 3 \\
13 \cdot 0 \\
21 \cdot 4 \\
8 \cdot 0 \\
6 \cdot 8 \\
14 \cdot 8 \\
13 \cdot 6 \\
8 \cdot 0 \\
18 \cdot 1 \\
10 \cdot 2 \\
15 \cdot 0 \\
14 \cdot 1 \\
4 \cdot 0 \\
0.5\end{array}$ & $\begin{array}{r}5 \cdot 9 \\
8 \cdot 8 \\
13 \cdot 3 \\
5 \cdot 4 \\
5 \cdot 3 \\
9 \cdot 4 \\
9 \cdot 0 \\
5 \cdot 9 \\
10 \cdot 8 \\
7 \cdot 5 \\
9 \cdot 4 \\
8 \cdot 2 \\
2.9 \\
0 \cdot 3\end{array}$ & $\begin{array}{l}2 \cdot 6 \\
3 \cdot 2 \\
1 \cdot 7 \\
4 \cdot 4 \\
4 \cdot 4 \\
3 \cdot 8 \\
3 \cdot 0 \\
3 \cdot 3 \\
3 \cdot 4 \\
3 \cdot 8 \\
3 \cdot 9 \\
4 \cdot 0 \\
3 \cdot 6 \\
4 \cdot 6\end{array}$ & $\begin{array}{l}11 \\
11 \\
22 \\
10 \\
13 \cdot 5 \\
13 \cdot 5 \\
11 \\
11 \\
14 \\
11 \\
11 \\
11 \\
13 \\
11\end{array}$ & $\begin{array}{l}46 \\
40 \\
64 \\
47 \\
55 \\
55 \\
43 \\
57 \\
56 \\
43 \\
65 \\
36 \\
41 \\
36\end{array}$ & $\begin{array}{r}185 \\
125 \\
95 \\
95 \\
160 \\
105 \\
70 \\
185 \\
320 \\
75 \\
120 \\
55 \\
55 \\
60\end{array}$ & $\begin{array}{r}103 \\
69 \\
15 \\
56 \\
69 \\
57 \\
53 \\
49 \\
45 \\
56 \\
21 \\
35 \\
52 \\
65\end{array}$ & $\begin{array}{c}200 \\
161 \\
- \\
207 \\
- \\
273 \\
304 \\
308 \\
137 \\
484 \\
230 \\
226 \\
214 \\
300\end{array}$ & $\begin{array}{r}8 \cdot 8 \\
9 \cdot 0 \\
7 \cdot 7 \\
9 \cdot 2 \\
8 \cdot 9 \\
8 \cdot 3 \\
9 \cdot 1 \\
- \\
8 \cdot 9 \\
10 \cdot 2 \\
10 \cdot 3 \\
10 \cdot 6 \\
8 \cdot 5 \\
9 \cdot 4\end{array}$ & $\begin{array}{l}2 \cdot 9 \\
3 \cdot 0 \\
3 \cdot 6 \\
5 \cdot 3 \\
3 \cdot 2 \\
3 \cdot 8 \\
6 \cdot 2 \\
-1 \\
3 \cdot 8 \\
4 \cdot 5 \\
3 \cdot 9 \\
4 \cdot 4 \\
4 \cdot 4 \\
6 \cdot 1\end{array}$ \\
\hline $1 \cdot 0$ & 0.5 & $2 \cdot 9$ & 15 & 54 & 90 & 40 & 165 & $8 \cdot 5$ & $4 \cdot 0$ \\
\hline
\end{tabular}

leficiency.

oil, $12.5 \mathrm{~g}$ skim milk powder, $14.0 \mathrm{~g}$ dextrose, $1 \mathrm{~g}$ polyethylene glycol (PEG), and $100 \mathrm{ml}$ water) was introduced into the stomach through a gastric tube. Intestinal contents were aspirated, pancreatic lipase was immediately inactivated by heat, and samples from each half-hour were pooled. Collection was usually continued for 2 hours depending on the flow of juice. Total concentrations of lipid and bile salts were measured in each half-hour pool.

To separate the aqueous phase from the lipid phase, a sample of intestinal contents from each 30-minute period was centrifuged in an International 40-B ultracentrifuge at a force of $10^{5} \mathrm{~g}$ (mean) for 3 hours at 25 to $30^{\circ} \mathrm{C}$. The lipid phase was removed by suction and the [I

n 15 cases

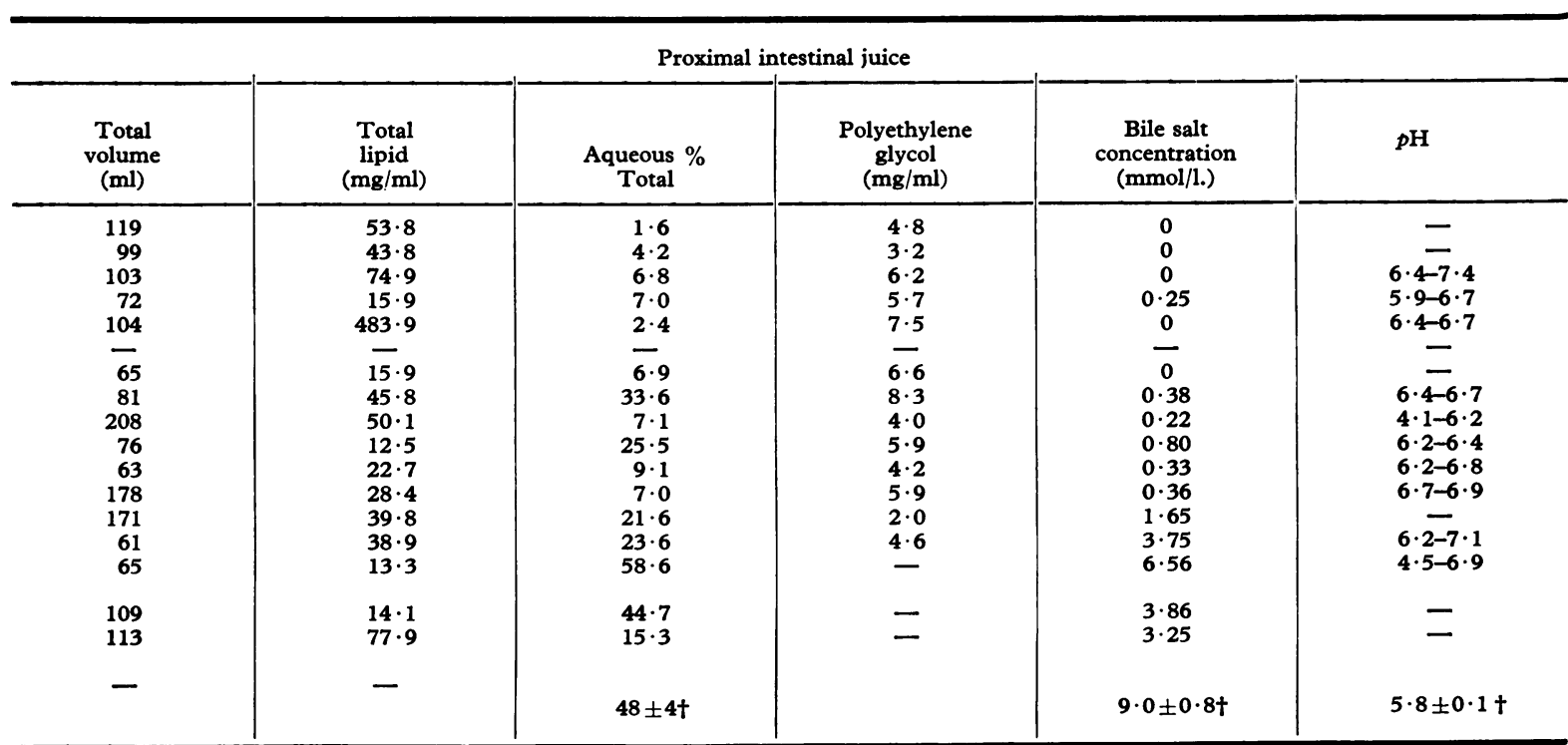


clear, aqueous phase aspirated by means of a long number 20 needle carefully passed down from the mouth of the tube. Lipid was extracted from $2 \mathrm{ml}$ samples of both whole juice and the aqueous phase, and was measured gravimetrically by the technique of Jeejeebhoy, Ahmed, and Kozak (1970). This utilized a two-solvent system which extracted all the glycerides and fatty acid, some of the phospholipid, but none of the conjugated bile salts.

Bile salt concentration was measured in a portion of the pooled intestinal contents in each case (Dr. K. N. Jeejeebhoy). After extraction of neutral steroids and saponification of taurine and glycine conjugates, free bile acids were extracted, converted first to their methyl esters, then to trimethyl silyl derivatives which were determined quantitatively by gas-liquid chromatography using $5 a$-cholestane as an internal standard. The method described by Grundy, Ahrens, and Miettinen (1965) to measure as little as $0.05 \mathrm{mg}$ bile salts was adapted for use with $2 \mathrm{ml}$ aliquots of intestinal juice.

The $p \mathrm{H}$ of intestinal contents was measured with a glass electrode and polyethylene glycol concentration determined turbidimetrically after precipitation of protein (Hyden, 1956).

\section{Results}

Clinical assessment (Table I). 11 of the 15 patients were girls; all but 3 were underweight and only 4 were of average height. The patients with extrahepatic biliary atresia were younger $(6 \pm 5$ months $)^{\star}$ than the rest $(47 \pm 27$ months $) . \star$

12 patients were jaundiced; 6 probably had portal hypertension on the basis of splenomegaly, oesophageal varices, and large venous collaterals; 3 had pruritus; 2 bruised easily; 1 had recurrent epistaxis; and 1 had xanthomas. Diarrhoea was a complaint in only 1 patient.

Hepatic function (Table I). Total serum bilirubin was increased in 13 cases and in 12 conjugated bilirubin was also raised. All had raised serum concentrations of SGOT; most had raised concentrations of alkaline phosphatase and cholesterol. Those without hyperbilirubinaemia retained bromsulphalein abnormally. In 3 patients, 2 with extrahepatic biliary atresia, there was evidence of advanced hepatocellular damage, as judged by decreased serum albumin concentrations and abnormal prothrombin and partial thromboplastin times, not correctable by parenteral administration of vitamin $\mathrm{K}$.

Fat absorption (Table II). Faecal fat excretion exceeded $15 \%$ of dietary intake in all but 4 cases. The mean for the group was $27 \pm 16 \%$; those with extrahepatic biliary atresia $(31 \pm 13 \%) \star$ did not differ from the others $(23 \pm 18 \%)^{\star}$. Lecithin,

$\star$ Mean \pm SD. administered by mouth, had no significant effect on faecal fat excretion, in either 7 cases of extrahepatic biliary atresia or in 2 with incomplete biliary obstruction.

Fasting concentrations of vitamin $A$ in serum were abnormally low in all but 6 patients. 4 of these and 2 additional patients had a normal rise after an oral dose of the vitamin. 2 of those with extrahepatic biliary atresia had a normal rise as compared to 4 of the 5 other patients.

Total serum calcium concentrations were normal in all cases when referred to albumin concentrations. No rickets was found at the time of study, though it had previously occurred in 1 patient (Case 9).

\section{Intestinal contents (Table II).}

Volume. The total volume of juice obtained from each patient during the total collection period varied greatly. The mean was $104 \pm 46 \mathrm{ml}$ for the entire group. There were no significant differences between groups with and without total biliary tract obstruction or between those with and without steatorrhoea.

Dilution. Polyethylene glycol concentrations measured in aspirated contents after administration of the test meal gave an estimate of the degree of dilution of the water soluble constituents of the meal by intestinal secretions. Mean concentrations ranged from $2 \cdot 0$ to $8 \cdot 3 \mathrm{mg} / \mathrm{ml}$ suggesting about a two- to sevenfold dilution. There was no significant difference between those with biliary atresia and the rest, or between those with steatorrhoea and those with normal fat absorption.

Fat content. The absolute quantity of lipid extracted from whole juice $(16 \cdot 6 \pm 39 \cdot 2 \mathrm{mg} / \mathrm{ml})^{\star}$ and from the aqueous phase $(5 \cdot 6 \pm 4 \cdot 5 \mathrm{mg} / \mathrm{ml})^{\star}$ varied greatly within the group. A more definite pattern was found when the degree of solubilization of lipid in the aqueous phase was calculated as a percentage of the total lipid found in the intestinal contents. Incorporation into the aqueous phase was significantly less in patients with steatorrhoea than in those with normal absorption ( $P<0.001)$. Furthermore, this was apparent during each of the four collection periods, but was most striking during the first hour of the study when solubilization rose sharply in the latter group but decreased progressively in those with steatorrhoea (Fig. 1).

The relation of daily fat excretion to the percentage of lipid solubilized was shown by the method of least squares to be exponential (Fig. 2). One patient showed a greater degree of steatorrhoea than would have been predicted from the fairly normal

\footnotetext{
$\star$ Mean \pm SD.
} 


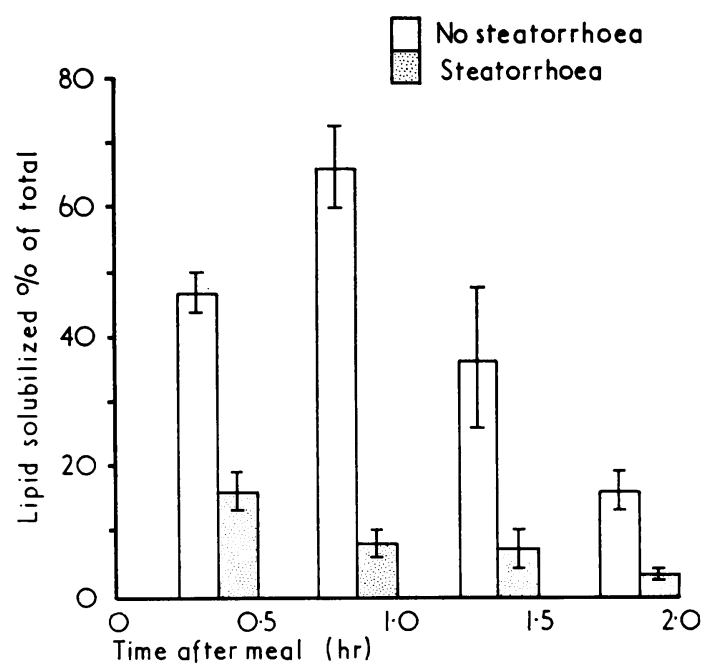

FIG. 1.-The proportion of lipid solubilized (mean $\pm S E$ ) in proximal intestinal contents during each period of digestion was significantly less in patients with steatorrhoea than in those who absorbed fat normally.

percentage of fat $(25 \%)$ found in the aqueous phase of intestinal juice.

Bile salts. Each patient's mean concentration during the period of study is shown in Table II. The overall mean was $1.02 \pm 0.50 \mathrm{mmol} / 1$. s $^{\star}$ which

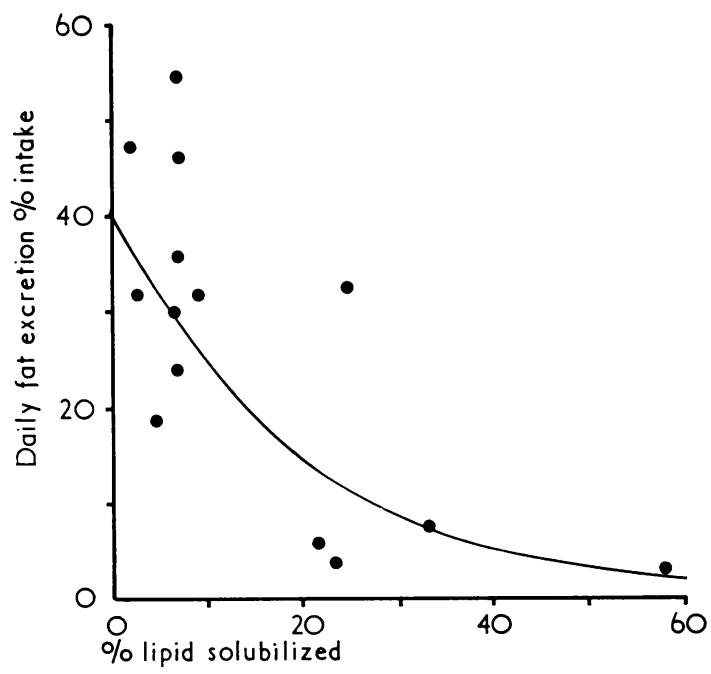

FIG. 2.-The relation of daily fat excretion to lipid solubilization is exponential, $y=41 \exp (-0.05 x)$. A similar curve can be constructed for fat excretion and bile salt concentration.

$\star M e a n \pm S E$ is below the critical micellar concentration (CMC) for conjugated bile salts (Hofmann, 1968). The 5 children in whom no bile salts could be detected have no doubt caused the low mean and the apparently skewed distribution. Normal concentrations were found in those who absorbed fat normally, though all had lower concentrations than the mean reported in adults (Go et al., 1970; Badley et al., 1970). Fig. 3 shows that there was a strong

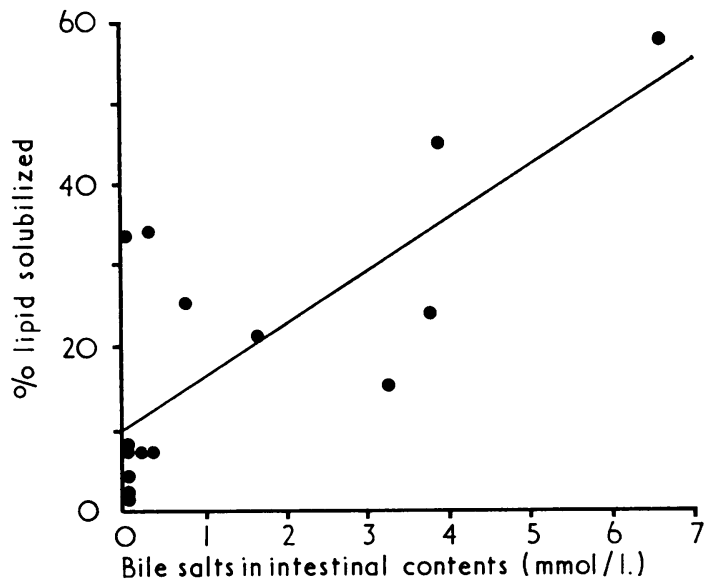

FIG. 3.-Linear relation of lipid solubilization to concentration of bile salts in proximal intestinal contents, $y=10 \cdot 2+6 \cdot 4 x$.

positive correlation between solubilization of dietary fat and bile salt concentration in intestinal contents $(r=+0 \cdot 84)$. Hence, it is not surprising that the relation of daily fat excretion to bile salt concentration is similar in type to that in Fig. 2, and it is noteworthy that the bile salt concentration, above which normal fat absorption may be expected, is close to the critical micellar concentration of $2 \mathrm{mmol} / \mathrm{l}$.

The positive intercept in the regression equation (Fig. 3) suggests that a small amount of lipid, approximately $10 \%$, might be solubilized even in the absence of bile salts. Surprisingly, one patient with extrahepatic biliary atresia solubilized a third of the luminal lipid and had a low faecal fat excretion despite a negligible concentration of bile salts.

The $p \mathrm{H}$ of intestinal contents did not differ from published normal figures (Go et al., 1970). In comparing groups with and without steatorrhoea and those with and without extrahepatic biliary atresia, there were no differences.

\section{Discussion}

Our studies show the capacity of the infant to assimilate fat in the presence of negligible quantities 
of bile salts in the upper intestinal lumen. Steatorrhoea was expected to be found because of the roles played by bile salts in normal fat absorption, the most important being to assist in dispersal of lipolytic products into an aqueous micellar phase in which they can reach the absorptive cell (Hofmann and Small, 1967; Johnston, 1968). Burke and Danks (1966) found a comparable high incidence of steatorrhoea in a similar group of patients.

In our patients with steatorrhoea luminal bile salt concentrations were below the critical micellar concentration (CMC) for conjugated bile salts under physiological conditions (Hofmann, 1968). The concentration of luminal bile salts bore no relation to the degree of dilution by endogenous secretions, but closely paralleled the degree of lipid solubilization during digestion of a fat meal. Our findings support the conclusion that in these patients luminal depletion of bile salts interfered with the normal solubilization of dietary lipid, leading to steatorrhoea. Similar findings have been reported in other patients with decreased luminal concentrations of bile salts : adults with external biliary fistulae (Porter et al., 1971) and cirrhosis (Atkinson, Nordin, and Sherlock, 1956; Krone et al., 1968; Badley et al., 1970; Miettinen and Siurala, 1971; Losowsky and Walker, 1969; Sun et al., 1967), and after extensive ileal resection (Krone et al., 1968; Van Deest et al., 1968; Hardison and Rosenberg, 1967).

The explanation for absent or grossly diminished concentrations of bile salts in the bowel lumen is obvious in our cases of biliary atresia. The relative importance of obstruction and hepatocellular failure in those with incomplete obstruction cannot be finally determined from these data. 3 patients with jaundice (Cases 10-12) had subnormal bile salt concentration and steatorrhoea, while those with absent or subclinical icterus (Cases 13-15) had normal bile salts and fat absorption. A single patient, however, with definite evidence of liver failure in the absence of any obstruction (Case 15), had the highest mean bile salt concentration of the group.

In these patients with biliary atresia more severe steatorrhoea might have been anticipated. Alternate routes of absorption are open to normal dietary lipids bypassing solubilization in micelles. Pancreatic lipolysis occurs in vitro in the absence of bile salts (Heath and Morris, 1963), and though aqueous solubilization of monoglyceride is very low, fatty acid has a definite solubility (Lucassen, 1966; Rosano et al., 1966). In rats (Hamilton, 1971) and in man (Hoffman and Hofmann, 1972) absorption of fatty acid from emulsions has been shown. In man absorption by this route is less rapid than from micelles, but it may extend throughout the length of the small bowel (Porter et al., 1971). In our cases of biliary atresia, up to $6.9 \%$ of luminal lipid could be extracted from the aqueous phase, and the positive intercept of the regression equation between bile salt and aqueous lipid concentrations suggested that approximately $10 \%$ might be solubilized in the absence of bile salts. Increased $p \mathrm{H}$ would increase fatty acid solubility, but our finding of a normal $p \mathrm{H}$ range is compatible with the presence of some fatty acid in molecular solution. The $p \mathrm{H}$ of intestinal contents of bile-deprived dogs is normal (Knoebel and Ryan, 1963).

Vitamin A absorption measured indirectly by the response in serum to an oral dose was in general diminished, an expected finding since bile is essential for the normal absorption of the fat soluble vitamin (Zachman, Dunagin, and Olson, 1966; Gagnon and Dawson, 1968; Forsgren, 1969). In several patients there was no relation between data on vitamin A absorption and faecal fat excretion or luminal bile salt concentration. In other malabsorptive disorders, such as coeliac disease, the test correlates poorly with steatorrhoea (Hamilton, Lynch, and Reilly, 1969). The absence of rickets when our patients were studied undoubtedly reflects the administration of supplemental vitamin D to these infants before the study, since this fat soluble vitamin, too, is dependent on bile for normal absorption (Avioli et al., 1966; Forsgren, 1969). Indeed, Case 9 who had had severe metabolic bone disease in association with obstructive jaundice healed only when ultraviolet light therapy was added to large doses of vitamin $\mathrm{D}$.

Modai and Theodor (1970) suggested that endogenous amphipaths such as lysolecithin and phosphatidic acid may improve lipid solubilization in patients with deficient luminal concentrations of bile salts. Our study indicates that administration of additional lecithin does not improve total fat absorption when bile salts are reduced or absent from the upper intestinal lumen. Any explanation for the failure of lecithin to benefit absorption is speculative. It may have failed because it actually is ineffective under the study conditions or because it failed to reach the region where it could influence fat absorption because of hydrolysis or rapid proximal absorption.

We thank the nurses and nutritionists of the Clinical Investigation Unit, Hospital for Sick Children, for their expert assistance; Drs. James Weber and Bernard Laski for allowing us to investigate patients under their care; Dr. K. N. Jeejeebhoy, Department of Medicine, University of Toronto, for bile salt concentration measurements; Mr. M. Khan and Dr. D. G. Butler for 
technical assistance; and Mrs. Marilyn McKee and Miss P. Donovan for secretarial help. J.F.T.G. was recipient of Elizabeth Arbuthnot Dyson Bequest, University of Toronto.

\section{REFERENCES}

Atkinson, M., Nordin, B. E. C., and Sherlock, S. (1956). Malabsorption and bone disease in prolonged obstructive jaundice. Quarterly fournal of Medicine, 25, 299.

Avioli, L., Lee, S. W., McDonald, J., and Deluca, H. (1966). Hepatic metabolism and biliary excretion of ${ }^{3} \mathrm{H}$-vitamin $\mathrm{D}_{3}$ in man. (Abst.) Clinical Research, 14, 432.

Badley, B. W. D., Murphy, G. M., Bouchier, I. A. D., and Sherlock, S. (1970). Diminished micellar phase lipid in patients with chronic nonalcoholic liver disease and steatorrhoea. Gastroenterology, 58, 781 .

Burke, V., and Danks, D. M. (1966). Medium-chain triglyceride diet: its use in treatment of liver disease. British Medical Fournal, 2, 1050.

Forsgren, L. (1969). Studies on the intestinal absorption of labelled fat-soluble vitamins $(A, D, E$, and $K$ ) via the thoracic duct lymph in the absence of bile in man. Acta Chirurgica Scandinavica, 135, Suppl. 399, 1.

Gagnon, M., and Dawson, A. M. (1968). The effect of bile on vitamin A absorption in the rat. Proceedings of the Society for Experimental Biology and Medicine, 127, 99.

Ghadimi, H., and Sass-Kortsak, A. (1961). Evaluation of the radioactive Rose-Bengal test for the differential diagnosis of obstructive jaundice in infants. New England fournal of Medicine, 265, 351.

Go, V. L. W., Poley, J. R., Hofmann, A. F., and Summerskill, W. H. J. (1970). Disturbances in fat digestion induced by acidic jejunal pH due to gastric hypersecretion in man. Gastroenterology, 58, 638.

Gomori, G. (1942). A modification of the colorimetric phosphorus determination for use with the photoelectric colorimeter. Fournal of Laboratory and Clinical Medicine, 27, 955.

Grundy, S. M., Ahrens, E. H., Jr., and Miettinen, T. A. (1965). Quantitative isolation and gas-liquid chromatographic analysis of total fecal bile acids. Fournal of Lipid Research, 6, 397.

Hamilton, J. D. (1971). The absorption of oleic acid from emulsion and micellar solution. Biochimica et Biophysica Acta, 239, 1.

Hamilton, J. R., Lynch, M. J., and Reilly, B. J. (1969). Active coeliac disease in childhood. Quarterly fournal of Medicine, 38, 135.

Hardison, W. G. M., and Rosenberg, I. H. (1967). Bile-salt deficiency in the steatorrhoea following resection of the ileum and proximal colon. New England fournal of Medicine, 277, 337.

Hardisty, R. M., and Ingram, G. I. C. (1965). Bleeding Disorders, p. 274. Blackwell, Oxford.

Heath, T. J., and Morris, B. (1963). The role of bile and pancreatic juice in the absorption of fat in ewes and lambs. British fournal of Nutrition, 17, 465.

Hoffman, N. E., and Hofmann, A. F. (1972). Absorption rates of micellar vs. non-micellar oleic acid: jejunal perfusion studies. (Abst.) Gastroenterology, 62, 763.

Hofmann, A. F. (1968). Functions of bile in the alimentary canal. In Handbook of Physiology, Vol. 5, Section 6, p. 2507. American Physiological Society, Washington.

Hofmann, A. F., and Borgstrom, B. (1964). The intraluminal phase of fat digestion in man: the lipid content of the micellar and oil phases of intestinal content obtained during fat digestion and absorption. Fournal of Clinical Investigation, 43, 247.
Hofmann, A. F., and Small, D. M. (1967). Detergent properties of bile salts. Correlation with physiological function. Annual Review of Medicine, 18, 333.

Hyden, S. (1956). A turbidimetric method for the determination of higher polyethylene glycols in biological materials. Annals of the Royal Agricultural College of Sweden, 22, 139.

Jeejeebhoy, K. N., Ahmed, S., and Kozak, G. (1970). Determination of fecal fats containing both medium and long chain triglycerides and fatty acids. Clinical Biochemistry, 3, 157.

Johnston, J. M. (1968). Mechanism of fat absorption. In Handbook of Physiology, Vol. 3, Section 6, p. 1353. American Physiological Society, Washington.

King, E. J., and Wootton, I. D. P. (1956). Microanalysis in Medical Biochemistry, 3rd ed., p. 83. Grune and Stratton, New York.

Knoebel, L. K., and Ryan, J. M. (1963). Digestion and mucosal absorption of fat in normal and bile-deficient dogs. American Journal of Physiology, 204, 509.

Krone, C. L., Theodor, E., Sleisenger, M. H., and Jeffries, G. H. (1968). Studies on the pathogenesis of malabsorption. Lipid hydrolysis and micelle formation in the intestinal lumen. Medicine, 47, 89.

Losowsky, M. S., and Walker, B. E. (1969). Liver disease and malabsorption. Gastroenterology, 56, 589.

Lucassen, J. L. (1966). Hydrolysis and precipitates in carboxylate soap solutions. Fournal of Physical Chemistry, 70, 1824.

MacIntyre, I. (1961). Flame photometry. Advances in Clinical Chemistry, 4, 1.

Miettinen, T. A., and Siurala, M. (1971). Bile salts, sterols, sterol esters, glycerides and fatty acids in micellar and oil phases of intestinal contents during fat digestion in man. Zeitschrift für Klinische Chemie und Klinische Biochemie, 9, 47.

Modai, M., and Theodor, E. (1970). Intestinal contents in patients with viral hepatitis after a lipid meal. Gastroenterology, 58, 379.

Porter, H. P., Saunders, D. R., Tytgat, G., Brunser, O., and Rubin, C. E. (1971). Fat absorption in bile fistula man; a morphological and biochemical study. Gastroenterology, 60, 1008.

Rosano, H. L., Breindel, K., Schulman, J. H., and Eydt, A. J. (1966). Mechanisms of ionic exchange with carrier molecules through nonaqueous liquid membranes. Fournal of Colloid Interface Science, 22, 58.

Sass-Kortsak, A., Bowden, D. H., and Brown, R. J. K. (1956). Congenital intrahepatic biliary atresia. Pediatrics, 17, 383.

Silverberg, M., and Davidson, M. (1970). Nutritional requirements of infants and children with liver disease. American fournal of Clinical Nutrition, 23, 604.

Sun, D. C. H., Albacete, R. A., and Chen, J. K. (1967). Malabsorption studies in cirrhosis of the liver. Archives of Internal Medicine, 119, 567.

Van Deest, B. W., Fordtran, J. S., Morawski, S. G., and Wilson, J. D. (1968). Bile salt and micellar fat concentration in proximal small bowel contents of ileectomy patients. Fournal of Clinical Investigation, 47, 1314.

Van de Kamer, J. H., ten Bokkel Huinink, H., and Weyers, H. A. (1949). A rapid method for the determination of fat in feces. fournal of Biological Chemistry, 177, 347.

Weber, A., and Roy, C. C. (1972). The malabsorption associated with chronic liver disease in children. Pediatrics, 50, 73.

Zachman, R. D., Dunagin, P. E., Jr., and Olson, J. A. (1966). Formation and enterohepatic circulation of metabolites of retinol and retinoic acid in bile duct-cannulated rats. Fournal of Lipid Research, 7, 3.

Correspondence to Dr. J. F. T. Glasgow, The Nuffield Department of Child Health, The Queen's University of Belfast, Institute of Clinical Science, Grosvenor Road, Belfast BT12 6BJ, Northern Ireland. 